\title{
Open Access Dermatology Publishing: No Citation Advantage Yet
}

\author{
Laura J. Umstattd ${ }^{1}$, Marcus A. Banks ${ }^{2}$, Jeffrey I. Ellis ${ }^{3,4,5}$ and Robert P. Dellavalle ${ }^{*, 6,7}$ \\ ${ }^{I}$ University of Texas Medical Branch at Galveston, USA \\ ${ }^{2}$ Kalmanovitz Library and Center for Knowledge Management, University of California, San Francisco, San Francisco, \\ CA, USA \\ ${ }^{3}$ Department of Dermatology, SUNY Downstate Medical Center, Brooklyn, NY, USA \\ ${ }^{4}$ JournalReview.org \\ ${ }^{5}$ Department of Medicine, Division of Dermatology, North Shore Hospital, Manhasset, NY, USA \\ ${ }^{6}$ Department of Veterans Affairs Medical Center, Denver, CO, USA \\ ${ }^{7}$ Department of Dermatology, University of Colorado at Denver, School of Medicine, Denver, CO, USA
}

\begin{abstract}
Background: Open access journals are a new publication model for sharing scientific information.
Objective: To compare the citation frequency of articles published by the same author in traditional pay-for-access and open access dermatology journals.

Methods: Articles by authors who published in the open access dermatology journal with the most citations and in any of the five pay-for-access journals with the highest h-indices (Journal of Investigative Dermatology, Journal of the American Academy of Dermatology, Archives of Dermatology, British Journal of Dermatology, Dermatologic Surgery) from January 1, 2005 to December 31, 2007, were identified. Article citation frequencies were determined using Google Scholar. The citation rates were then adjusted for the bias of perceived prestige of each journal by dividing each article's number of citations by the impact factor of the journal in which it was published. Statistical analysis was performed using the Wilcoxon signed-rank test on both raw and impact factor adjusted data.
\end{abstract}

Results: BioMed Central (BMC) had the most citations of any open access dermatology journal. Thirty-four authors published in both BMC Dermatology and a leading traditional dermatology journal during the study time period. Twenty-four authors had higher average citations to articles in traditional journals; 7 authors had higher average citations to articles in BMC Dermatology; 3 authors had equal average citations. These results were statistically significant with a two tailed pvalue of 0.0014 . After weighting citation rates by journal impact factor, 20 authors now had higher average citation rates for their BMC publications and 14 authors had higher citation rates for articles published in traditional, pay-for-access journals, with a p-value of 0.39 .

Limitations: A definitive study would require the publication of the same articles simultaneously in both open and payfor-access journals such duplicate publication is forbidden by all the journals investigated. In addition, it is possible that authors submit better papers to traditional dermatology journals, which would inherently skew the outcome of this study.

Conclusion: Our study finds no statistical difference in citations rates of recent articles by the same authors published in dermatology pay-for-access and the leading open access dermatology journals after weighting by journal impact factor.

\section{INTRODUCTION}

The Open Access movement attempts to revolutionize the availability of biomedical information by making all published papers available to all readers via the Internet without charge. An open access (OA) publication is defined as 1) freely available to all online readers, and 2) secured in a digital repository for long-term access [1]. Because articles published in the open access format are available to the general public without subscription or fee, open access publishing may result in wider readership and higher citation rates that

*Address correspondence to this author at the Department of Veterans Affairs, Dermatology Service, 1055 Clermont Street, Box 165, Denver, CO 80220, USA; Fax: 303-393-4686; E-mail: Robert.Dellavalle@uchsc.edu promote scientific discourse and author academic promotion and prestige. In this study we evaluate the claim that dermatology open access publishing increases citation rates.

\section{METHODS}

Open access dermatology journals were identified by searching a directory of Open Access Journals (http://www. doaj.org/doaj?func=subject\&cpid=43).

From the BioMed Central Dermatology web page (http://www.biomedcentral.com/bmcdermatol) every author of a paper classified as a "research article" or "database" published from January 2005 through December of 2007 was entered into an excel database with name, year of publication, and PubMed identifier (PMID) number of the article 
(found on PubMed link at the bottom of each citation). Articles listed as case reports or correspondence were excluded.

Table 1. Some Open Access Journals of Interest to Dermatologists, Year of Inception

\begin{tabular}{|l|c|}
\hline Anais Brasileiros de Dermatologia & 2003 \\
\hline BMC Dermatology & 2001 \\
\hline Clinical Dermatology & 2001 \\
\hline Dermatología Peruana & 2003 \\
\hline Dermatology Online Journal & 1995 \\
\hline Indian Journal of Dermatology & 2005 \\
\hline Indian Journal of Dermatology, Venereology and Leprology & 1995 \\
\hline The Internet Journal of Dermatology & 2001 \\
\hline Journal of the Egyptian Women's Dermatologic Society & 2004 \\
\hline Open Dermatology Journal & 2007 \\
\hline
\end{tabular}

Google Scholar (www.googlescholar.com) was then used to search for the article's title by entering the title within quotation marks in the Google Scholar search engine. Citation frequency, as found in the last line of the search result in the "Cited by" link, was recorded in the excel database. There are several other resources available to track citations, including Scopus and Web of Science, which have been noted to, at times, return disparate information [2]. Results of this study, however, are limited to information provided by Google Scholar because it is available to the public without a subscription. In addition, Web of Science provides no information for BMC Dermatology articles, and none of the authors of this paper have access either personally or through affiliated institutions to Scopus.

For each BMC author, PubMed was used to search for articles they published from January 2005 through December of 2007 using the "limits" tab and searching by author's Last name, First initial in the following journals: Journal of the American Academy of Dermatology, Journal of Investigative Dermatology, Archives of Dermatology, British Journal of Dermatology, and Dermatologic Surgery. These journals were selected for the study because they are the five dermatology journals with the highest h-indices [3].

Article results were then viewed in the MEDLINE format, and a paper was excluded from the database if was classified as a case report, or if it was classified as only one or more of the following publication types: Comment; Letter; Editorial; Research support, Non-U.S. Gov't; Research support, U.S. Gov't, P.H.S.; Research support, N.I.H., extramural. Papers that resulted from the PubMed search that were found to be from a different author than the one intended in the search (as noted by different first name, different middle initial or different institution of affiliation) were also excluded.

Under the author's name in the excel database, each of the articles meeting inclusion criteria was listed by PMID and year of publication. Google Scholar was then used to search these article titles for citation frequency as described above.
To account for perceived journal prestige, the citation frequency of each article was divided by the impact factor from 2006 of the journal in which it was published. The impact factors were obtained from the ISI Web of Science Journal Citation Reports, and are as follows: Journal of Investigative Dermatology (4.5), British Journal of Dermatology (3.3), Archives of Dermatology (2.9), Journal of the American Academy of Dermatology (2.6), and BioMed Central Dermatology (1.2). A Wilcoxon signed rank test for statistical significance was performed using the resulting impact-factor-adjusted citation means.

\section{RESULTS}

Twenty-nine articles were published in BioMed Central Dermatology from January 2005 through December of 2007; five of these articles are case reports, one is correspondence and thus were excluded from this study. One hundred and four different authors were identified from these 23 papers, and $34(33 \%)$ of these authors also published one or more articles meeting inclusion criteria in the following journals: Journal of the American Academy of Dermatology, Journal of Investigative Dermatology, Archives of Dermatology, and British Journal of Dermatology. No BMC Dermatology authors during this time period also published a research article in Dermatologic Surgery. The 71 authors that only had publications in BMC Dermatology fitting the inclusion criteria were excluded. The number of articles per author ranged from 2 to 19 .

The average number of citations for each author was compared between two groupings of articles: all BMC Dermatology articles, and all articles from the five other journals. Twenty-four authors $(70.6 \%)$ were found to have a higher citation rate for articles published in the traditional pay-for-access journals; seven authors (20.6\%) had higher citation rates for articles published in BMC Dermatology; three authors $(8.8 \%)$ had equal rates of citation from both groups. These results were statistically significant, with a two tailed $\mathrm{p}$ value of 0.0014 .

Once citation rates were adjusted for impact factor, twenty authors (59\%) had higher citation rates for BMC Dermatology articles and fourteen authors $(41 \%)$ had higher citation rates for articles published in traditional pay-foraccess journals. These results were not statistically significant, with a $p$ value of 0.39 .

The average number of citations per article was found to be the highest for the Journal of the American Academy of Dermatology at 12.7, followed by the British Journal of Dermatology at 5.6; the Journal of Investigative Dermatology at 4.4; BMC Dermatology at 1.9; and the Archives of Dermatology at 1.8. Table 2 provides Google Scholar derived impact factor weighted citation means.

\section{DISCUSSION}

The advent of the open access publishing movement has been made logistically possible by the internet which serves as a means for instantaneous and inexpensive delivery of information and by its spirit of egalitarianism and the sharing of ideas. The soul of the movement has its roots much 
Table 2. Impact Factor Weighted Google Scholar Mean Citations Per Article

\begin{tabular}{|c|c|c|c|c|}
\hline & $\mathbf{N}=17$ & $\mathrm{~N}=14$ & $\mathbf{N}=\mathbf{0}$ & $\mathbf{N}=\mathbf{3}$ \\
\hline \# of BMC Articles & 1 & 1 & $>1$ & $>1$ \\
\hline Weighted citation mean per article & 1.3 & 1.6 & ---- & 2.0 \\
\hline \# of Traditional Journal Articles & 1 & $>1$ & 1 & $>1$ \\
\hline Weighted citation mean per article & 0.95 & 1.7 & --- & 5.6 \\
\hline \multicolumn{5}{|c|}{ Two-tailed $\mathrm{p}$ value $=0.39$} \\
\hline \multicolumn{5}{|c|}{$\begin{array}{l}\text { Explanation of Table 2: } \\
\text { - } 17 \text { authors published one article in BMC and one article in a traditional journal, with } \\
\text { average citation rates of } 1.3 \text { and } 0.95 \text {, respectively. } \\
\text { - } 14 \text { authors published one article in BMC and more than one article in traditional } \\
\text { journals, with average citation rates of } 1.6 \text { and } 1.7 \text {, respectively. } \\
\text { - No authors published more than one article in BMC and only one article in a tradi- } \\
\text { tional journal. } \\
\text { - } 3 \text { authors published more than one article in both BMC and traditional journals, with } \\
\text { average citations of } 2.0 \text { and 5.6, respectively. }\end{array}$} \\
\hline
\end{tabular}

further back in history, as scholarly publishing has always been motivated by a desire for communication amongst peers for the purpose of advancing knowledge in their field and establishing credit for one's work [4]. Today, authors publishing in open access journals are motivated to do so by the ideal that anyone can have access to their work [4], and many authors favor the open access model due to increased exposure and potential citation of their work [5,6]. Further impetus for the movement has come from academic institutions and their libraries that are finding it financially difficult to maintain subscriptions to a sufficiently wide base of journals to satisfy the needs of all their institution's research endeavors [5].

Some publishers question the "citation advantage" of open access [7], and representatives of many scientific societies fear that open access will cause the loss of critical subscription income [8]. Since journals pay for open access by charging authors additional fees (often in excess of $\$ 1000$ US per article), opponents have alternatively named open access the "author pays" publishing model $[9,10]$. Authors at institutions that have secured an institutional membership (usually through their library) may be charged reduced open access publishing fees, and authors who cannot afford additional fees for open access may apply to have them waived $[11,12]$. When considering fees charged for publication in open access journals, one must keep in mind that many major subscription-based journals often require that authors pay fees for pages, figures and reprints as well [6]. In addition to concern over cost, authors also cite their lack of familiarity with open access journals as a major reason why they do not publish in open access, along with the perception that open access journals are less prestigious, have lower impact and smaller readerships than subscription based journals [4].

The other means of increasing access is for authors to self-archive their work by posting their manuscripts online, which is often referred to as the "green road" to open access, whereas open access journals have been called the "gold road". As many publishers now have policies allowing authors to put their post-publication works online [6], selfarchiving has the potential to greatly expand the amount of open access information available. Both methods of achieving open access maintain the standards of scholarly publica- tion, as both employ the process of peer review [6]. Major funding agencies such as the U.S. National Institutes of Health (NIH) and the Welcome Trust now require open access to publications resulting from funded projects and noncompliance with this policy may affect future funding of the authors [13, 14].

As noted above, several studies demonstrate the citation advantage of publishing in open access journals, but these studies were not restricted to dermatology publications. For Google Scholar citation counts, more authors (70.6\%) had higher average citations for articles published in the traditional journals, indicating a citation advantage over open access publications. After adjusting for journal impact factor though, this citation advantage is neutralized. This adjustment was made in order to eliminate bias concerning prestige of journals, which may influence where a person prefers to select articles as references for their own work. Possible explanations for authors having lower citation frequencies for open access publications include: the lower citation rates of BMC Dermatology are a reflection of the comparative youth of this journal and authors choose to submit their better or more influential manuscripts (which are more likely to be cited often regardless of the journal they are published in) to journals with higher impact factors. Although this study cannot determine precisely the reason, we conclude that the citation advantage open access publishing provides in other fields has yet to arrive in dermatology.

\section{ABBREVIATIONS}

$\begin{array}{lll}\mathrm{BMC} & = & \text { BioMed Central } \\ \mathrm{OA} & = & \text { Open access } \\ \mathrm{PMID} & = & \text { PubMed identifier } \\ \mathrm{NIH} & = & \text { National Institutes of Health }\end{array}$

\section{CONFLICTS OF INTEREST}

Dr. Dellavalle is an unpaid advisor to www.JournalReview.org and serves on the editorial boards of the following dermatology journals: JAAD, Archives of Dermatology, JID and BMC Dermatology.

Mr. Banks is the former editor-in-chief of the open access journal Biomedical Digital Libraries.

This study began with Colorado Health Informatics Collaboration interdisciplinary discourse supported by academic enrichment funds from the University of Colorado Denver, School of Medicine.

Dr. Ellis is the founder of JournalReview.org.

We have received no funding to write this article.

\section{REFERENCES}

[1] Bethesda Statement on Open Access Publishing. 2003. Available at: http://www.earlham.edu/ peters/fos/bethesda.htm. Accessed 9/3/07.

[2] Bakkalbasi N, Bauer K, Glover J, Wang L. Three options for citation tracking: Google Scholar, Scopus and Web of Science. Biomed Digit Libr 2006; 3:7.

[3] SCImago. (2007). SJR - SCImago Journal \& Country Rank. Retrieved April 25, 2008, from http://www.scimagojr.com

[4] Swan A, Brown S: JISC/OSI journal authors survey report, 2004. Truro, UK: Key Perspectives Ltd. Available at: http://www.jisc.ac. u/uploaded_documents/ACF655.pdf. Accessed 11/01/2007. 
[5] Lawrence S. Free online availability substantially increases a paper's impact. Nature 2001;411;521. Preprint available at: http:// citeseer.ist.psu.edu/online-nature01/. Accessed 9/3/07.

[6] Albert KM. Open access: implications for scholarly publishing and medical libraries. J Med Libr Assoc 2006; 94: 253-262. Available at: http://www.pubmedcentral.nih.gov/articlerender.fcgi?artid=152 5322. Accessed 9/3/07.

[7] Craig ID, Plume AW, McVeigh ME, Pringle J, Amin M. Do open access articles have greater citation impact?: A critical review of the literature. Journal of Informetrics 2007; 1: 239-248. Preprint available at: http://www.publishingresearch.net/Citations-Summary Paper3_000.pdf.pdf. Accessed 9/3/07.

[8] Frank $M$. Access to the scientific literature-a difficult balance. $\mathrm{N}$ Engl J Med 2006; 354: 1552-1555. Available at: http://content. nejm.org/cgi/content/full/354/15/1552 Accessed 9/3/07.

[9] McCabe MJ, Snyder CM. The best business model for scholarly journals: an economist's perspective. 2004. Nature Web Focus:
Access to the literature. Available at: http://www.nature.com/ nature/focus/accessdebate/28.html. Accessed: 9/3/07.

[10] Iverson C, Christiansen S, Flanagin A, et al. AMA manual of style: A guide for authors and editors, $10^{\text {th }}$ ed. Oxford University Press, 2007.

[11] BioMed Central: About Us: About Membership. Available at: http://www.biomedcentral.com/info/about/membership. Accessed 9/3/07.

[12] BioMed Central: For Authors: Article Processing Charges. Available at: http://www.biomedcentral.com/info/authors/apcfaq\#waiv ers. Accessed 9/3/07.

[13] National Institutes of Health. NIH public access policy: policy overview and frequently asked questions. Available at: http://public access.nih.gov/policy.htm. Accessed 11/11/2007.

[14] Wellcome Trust. Press releases, 2005. Available at: http://www. wellcome.ac.uk/doc\%5Fwtx026822.html. Accessed 11/11/2007.

(C) Umstattd et al.; Licensee Bentham Open.

This is an open access article distributed under the terms of the Creative Commons Attribution License (http://creativecommons.org/licenses/by/2.5/), which permits unrestrictive use, distribution, and reproduction in any medium, provided the original work is properly cited. 